\title{
INFLUÊNCIA DO TIPO DE COMBOIO EM OPERAÇÕES HIDROVIÁRIAS
}

\author{
G.V.Guimaraes ${ }^{1 *}$; P.R. Luquez ${ }^{1}$; F.L.F. Faria ${ }^{1}$, M.A.V. Silva ${ }^{2}$ \\ 1 Instituto Militar de Engenharia, 22290-270, Urca, Rio de Janeiro - RJ, Brasil. \\ 2 Universidade Federal do Rio de Janeiro, 21949-900, Cidade Universitária, Rio de Janeiro - RJ, Brasil. \\ *gabriella.vitorino@gmail.com
}

Artigo submetido em 10/08/2015 e aceito em 30/08/2015

\section{RESUMO}

$\mathrm{O}$ artigo apresenta uma análise da influência da escolha do tipo de comboio para navegação na hidrovia, tendo como enfoque o custo de transporte e a emissão de $\mathrm{CO} 2$. Para a análise de custo foram detalhados os itens que o compõe, verificando a influência do tipo comboio em cada componente. O item mais sensível na definição do comboio é a potência dos motores, que possui uma dependência direta com o consumo de combustível e, consequentemente, com a emissão de $\mathrm{CO} 2$ na atmosfera. A análise detalhada apresentada neste artigo foi capaz de identificar a melhor opção de operação na hidrovia em relação aos aspectos levantados neste estudo.

PALAVRAS-CHAVE: hidrovia, custos, operação.

\section{INFLUENCE OF TYPE OF CONVOY IN WATERWAYS OPERATIONS}

\begin{abstract}
The paper presents an analysis of the influence of the choice of convoy type for navigation in the waterway, focusing on shipping cost and $\mathrm{CO} 2$ emissions. For the cost analysis, the items that compose it have been detailed. The study verified the influence of the convoy type in each component. The most sensitive item in train
\end{abstract}

setting is engine power, which has a direct dependency on fuel consumption, and consequently,the emission of $\mathrm{CO} 2$ into the atmosphere. The detailed analysis presented in this article was able to identify the best operation option in the waterway in relation to the issues raised in this study.

KEYWORDS: waterway; costs; operation. 


\section{INTRODUÇÃO}

O Brasil possui uma matriz de transporte voltada para o modo rodoviário. Em 2005, ele representava $58 \%$, seguido do ferroviário (25\%), hidroviário $(13 \%)$, dutoviário $(3,6 \%)$ e aéreo $(0,4 \%)$. A falta de investimento em infraestrutura no setor de transportes ao longo dos anos gerou problemas como ineficiência, custos adicionais e acidentes. Nas hidrovias ocasionou restrições de calado, deficiências de sinalização e balizamento e restrições à navegação pela inexistência de eclusas. Porém, através do Plano Nacional de Logística - PNLT, desenvolveu-se um portfólio de investimento em que está previsto um total de 12.806,00 milhões de reais para o setor hidroviário. Após todas as ações planejadas, objetiva-se que em 2025 a nova matriz de transporte esteja mais equilibrada, e assim distribuída: modo rodoviário (30\%), ferroviário (35\%), hidroviário (29\%), dutoviário (5\%) e aéreo (1\%) (Ministério dos Transportes, 2010).

Em 2013, o Ministério dos Transportes divulgou o Plano Hidroviário Estratégico (PHE), que prevê a ampliação do transporte por hidrovias como alternativa de escoamento da produção agrícola e demais produtos. O objetivo do PHE é melhorar a qualidade das atuais hidrovias brasileiras e expandir a rede hidroviária em mais de 3 mil quilômetros, além de otimizar o seu potencial comercial. Portos como os de Paranaguá e Santos, por exemplo, têm grande volume de movimentação de cargas; no ano de 2013 ela foi de 1,56 milhões de toneladas (APPA, 2015) e 114.077.884 toneladas (Porto de Santos, 2015), respectivamente.

Considerando essa alta demanda, verifica-se a necessidade de medidas para melhorar sua eficiência, a exemplo do aumento de seus pátios de caminhões e aprimoramento de sistemas para evitar filas, para que assim eles estejam preparados para atender tamanha demanda. Parcela dessa carga é transportada através de comboios, sendo importante identificar qual tipo é mais viável trafegar sob vários aspectos, a exemplo do custo do custo de transporte e das emissões de $\mathrm{CO} 2$ na atmosfera, que é um dos gases do efeito estufa.

De acordo com Padovezi (2003), as eclusas são determinantes quanto às dimensões dos cascos das chatas. Ele diz que "as dimensões de sua câmera deverão nortear a fixação das dimensões máximas principais dos cascos (bocas, comprimento e calados)". O autor ainda ressalta a possibilidade do desmembramento do conjunto de chatas, flexibilizando as suas dimensões, e aumentando os tipos de operação que podem ser executadas. Além das eclusas, outros fatores que influenciam na determinação das dimensões possíveis de um comboio são os trechos com limitação de profundidade, curvas fechadas e trechos estreitos (Padovezi, 2003)

O transporte na hidrovia Tietê-Paraná caracteriza-se pela movimentação de cargas volumosas e de baixo valor agregado, tais como os granéis sólidos. Essa hidrovia se destaca de forma estratégica para escoar a produção de granéis do centro-oeste. De acordo com a Agência Nacional de Transporte Aquaviário - ANTAQ (2013), mais de um quarto da soja e um terço do milho foram transportados na hidrovia Tietê-Paraná, partiram de São Simão-GO e transbordaram para ferrovia para serem exportados.

Nesse contexto, este presente artigo pretende resolver a seguinte questão: é possível avaliar o impacto do custo de transporte e emissão de $\mathrm{CO} 2$ na atmosfera com a variação do tamanho de comboio em hidrovias? Tem-se como principal hipótese que existe diferença nos valores dessas duas variáveis de acordo com o tipo de comboio escolhido para operar. Para comprovar, farar-se-á uma comparação entre comboios de 2,4 e 6 chatas.

Considerando o grande potencial exportador do Brasil e os investimentos previstos para o setor hidroviário contidos no PNLT, tem-se no negócio de agência marítima uma oportunidade de empreendimento. Nesse contexto, o objetivo desse trabalho é avaliar o impacto no custo de transporte e na emissão de $\mathrm{CO} 2$ na atmosfera do setor hidroviário a partir do tipo de comboio escolhido para navegação (2, 4 ou 6 chatas), fazendo um estudo de caso na hidrovia Tietê-Paraná e na eclusa Nova Avanhandava. Para isso, ter-se-á como base o valor do custo de transporte calculado por Gonçalves (2008). 
O artigo está estruturado da seguinte forma: na seção 2 é apresentada uma visão geral da estrutura do transporte aquaviário, com um enfoque no sistema hidroviário brasileiro e do papel do armador no transporte marítimo, bem como os órgãos regulamentadores; na seção 3, método da pesquisa, explora-se a eclusa como gargalo de uma hidrovia, com enfoque na hidrovia Tietê-Paraná e na eclusa de Nova Avanhandava; na seção 4 é estudada a questão do valor do custo de transporte de comboio-tipo, com base no trabalho de Gonçalves (2008); e na seção 5 são versadas as conclusões finais do trabalho.

\section{REVISÃO BIBLIOGRÁFICA}

\subsection{Estrutura do Transporte Aquaviário}

No Brasil, a ordenação do transporte aquaviário é regida pela Lei n 9.432/1997, que define seis tipos de navegação: de apoio portuário - realizada exclusivamente nos portos e terminais aquaviário; de apoio marítimo - realizada para o apoio logístico a embarcações e instalações em águas territoriais nacionais e na Zona Econômica; de cabotagem - realizada entre portos ou pontos do território brasileiro; interior - realizada em hidrovias interiores; de longo curso - realizada entre portos brasileiros e estrangeiros; e de travessia - realizada transversalmente aos cursos dos rios e canais, entre dois pontos das margens, entre ilhas e margens e entre dois pontos de uma mesma rodovia ou ferrovia interceptada por corpo de água.

De acordo com Santana e Tachibana (2004), um projeto hidroviário é composto por quatro principais elementos físicos: as vias, as embarcações, as cargas e os terminais. É objetivo aplicar as vias em canalização, obras de regularização do leito dos rios, obras para estabilidade e proteção de margens, dragagens e derrocamentos de pontos específicos, elaboração de cartas náuticas eletrônicas dos rios, balizamento e sinalização dos rios e para sistemas de boias de amarração de embarcações. Para as embarcações, as tecnologias de utilização de radares, ecobatímetro, sistema de posicionamento global diferencial, boat thruster, empurrador com propulsão azimutal, casco duplo para o transporte de cargas perigosas e estratégia de tratamento da água de lastro e de incrustação em cascos de navios devem ser aplicadas. Os autores também afirmam que os impactos ambientais relacionados aos terminais ocorrem em dois instantes: na implantação e na operação.

De acordo com a ANTAQ, o Brasil apresenta seis bacias hidrográficas: São Francisco, Sul, Tocantins-Araguaia, Amazônica, Paraguai e Paraná-Tietê. No entanto, essas bacias apresentam suas particularidades, conforme afirma a Agência Nacional de Águas - ANA, "cada rio da Rede Hidrográfica Brasileira oferece condições bem diferentes de navegabilidade, no que diz respeito ao calado, largura da rota de navegação, raios das curvas presentes, presença de corredeiras, cachoeiras, barragens e eclusas, bem como às variações decorrentes do ciclo hidrológico" (ANA, 2005).

A região hidrográfica do Paraná, objeto deste estudo, tem uma extensão navegável de 1.668 km e como principais rios Paraná, Tietê, Paranaíba, Grande, Ivaí e Ivinhema. A hidrovia TietêParaná é composta por 10 eclusas: Barra Bonita, Bariri, Ibitinga, Promissão, Nova Avanhandava (sup.), Nova Avanhandava (Inf.), Três Irmãos (Sup.), Três Irmãos (Inf.), Jupiá e Porto Primavera. Elas têm, em média, $142 \mathrm{~m}$ de comprimento, $12 \mathrm{~m}$ de largura e 3,50 m de profundidade mínima. Elas foram construídas juntamente às barragens das usinas hidrelétricas (ANTAQ, 2010). Esta hidrovia é objeto de muitos estudos devido a sua importância econômica para o país e por ter recebido obras há mais tempo que as demais existentes no país.

As eclusas e barragens possibilitam a superação das adversidades do relevo, fazendo com que o transporte seja possível na via, contribuindo para a articulação entre os centros produtores, mercados consumidores internos e portos de exportação. Padovezi (2003) afirma que algumas 
eclusas não comportam cruzamento de embarcações, o que pode ocasionar filas, devendo assim considerar os tempos despendidos nas eclusagens e a verificação de desmembramentos quando da escolha do tipo de comboio a ser utilizado. A capacidade reduzida de uma eclusa faz com que essas atividades realizadas ao longo da hidrovia se tornem limitadas e impeçam o desenvolvimento nas áreas de influência da via.

\subsection{O papel do armador e órgãos regulamentadores}

De acordo com a Lei no 9.537/97, armador é a "pessoa física ou jurídica que, em seu nome e sob sua responsabilidade, apresta a embarcação com fins comerciais, pondo-a ou não a navegar por sua conta". Ele é um dos responsáveis pela embarcação. Assim, caso ela seja apreendida pela autoridade marítima, o proprietário, armador ou preposto responderá pelas "despesas relativas ao recolhimento e guarda da embarcação apreendida".

Plácido (2007) conceitua armador como "o responsável em ofertar navios que possam ser utilizados comercialmente entre países, são dessas empresas as obrigações e cuidados com a carga depois de transferida dos portos de embarque, até o descarregamento no porto de destino". No entanto, não é obrigatório que ele seja o dono do navio, pois ele pode terceirizar o serviço, alugando-o.

O armador deve preparar o navio para que ele tenha condições de operar de forma comercial, se responsabilizando pelo transporte marítimo. Esses armadores podem ter seus próprios escritórios ou terceirizar o serviço, de acordo com o tamanho de seu porte. Essa representação é chamada de Agência Marítima, que, segundo Keedi (2000) apud Plácido (2007), "é a empresa que representa o armador em determinado país, estado, cidade ou porto, fazendo a ligação entre este e o usuário do navio". De acordo com Silva (2004) apud Plácido (2007), "o agente é o representante do armador em terra, e deve apoiar o capitão do navio no abastecimento da embarcação repassando todas as informações pertinentes como: tipo do navio, tripulantes, tonelagem, etc".

No Brasil, os órgãos governamentais que regulam o transporte marítimo são o Ministério dos Transportes, a Secretaria de Transportes Aquaviário, o Departamento de Marinha Mercante, o Departamento dos Portos e o Tribunal Marítimo. Porém, o DMM é o responsável pelo controle dos registros de armadores, além de fretes, acordos bilaterais, conferência de fretes e outros assuntos relativos ao transporte marítimo brasileiro. De acordo com a ANTAQ, os instrumentos para fiscalização são: sistema de informações, sistema Mercante, convênios de cooperação com DPC e COMCONTRAN, convênios com agências reguladoras e órgãos estaduais voltados para o setor transportes, Unidades Regionais para fiscalização, convênio com Receita Federal e Manual de Procedimentos de Fiscalização.

Em relação à oferta de serviços no panorama brasileiro, de acordo com a ANTAQ as empresas que atuam na navegação interior têm como natureza de transporte: passageiros, veículos e cargas; passageiros e mistos e carga (carga geral, granéis sólidos e líquidos, ro-ro). As principais hidrovias e cargas movimentadas são, respectivamente: Amazonas - carga geral (ro-ro) e derivados de petróleo; Solimões - petróleo e GLP; Madeira - soja, fertilizantes, carga geral (ro-ro), derivados de petróleo e álcool; Paraguai - soja, minério de ferro e manganês, trigo e cimento; Paraná/Tietê soja, farelo, trigo, milho, insumos agrícolas e areia; e Jacuí/Taquari/Lagoa dos Patos - carvão, madeira e soja.

\section{MATERIAIS E MÉTODOS}

\subsection{A eclusa de nova Avanhandava e os gargalos do sistema}

A eclusa de Nova Avanhandava está localizada no rio Tietê - km 178, próximo a cidade de Buritama/SP, tem como finalidade a navegação e como gestor a Companhia Docas do estado de São Paulo - CESP. Seu comprimento é de $142 \mathrm{~m}$ e sua largura de 12,10 m. A eclusa superior tem 
profundidade entre mínima e máxima normal de 4,50 m e a eclusa inferior entre mínima normal 4,50 m e máxima normal de 9,50 m. em relação ao desnível, a esclusa superior entre máximos normais de $11,50 \mathrm{~m}$ e entre mínimos normais de $16,50 \mathrm{~m}$, e a eclusa inferior entre máximos normais 11,50 m e entre mínimos normais de 16,50 m (Ministério dos Transportes).

Segundo a ANTAQ, o volume de carga que passou pela eclusa Nova Avanhandava em comparação com o volume total transportado na hidrovia, de 2011 a 2013, foi: $34 \%$, 37\% e 49\%. O período compreendido entre maio a novembro foi responsável por $76 \%$ do total. Os produtos transportados foram soja, milho, madeira, farelo de soja e celulose. No entanto, ela necessita de constantes investimentos de melhoria, face à sua importância econômica e suas limitações de infraestrutura.

Devido à necessidade de uma boa operacionalidade de um sistema para que ele garanta que os serviços sejam prestados de maneira satisfatória. Assim, é importante destacar a importância de se identificar os principais gargalos que interferem na melhor utilização de uma eclusa, pois segundo Ribeiro et all. (2008), "os gargalos são os elementos que definem a capacidade de uma via de transporte, e no caso da hidrovia com eclusas, estas é que definem a capacidade da via".

Nelson Júnior (2008) elenca os gargalos da Hidrovia Tietê-Paraná que prejudicam o transporte de cargas, que são as pontes ferroviárias e rodoviárias baixas e sem proteção nos pilares, falta de sinalização de navegação em alguns trechos, baixo calado, canais de eclusagem muito estreitos e que impedem a passagem de comboios com um maior número de chatas, e outros. Ele também afirma que o alargamento dos canais de eclusagem "se configura como um dos principais obstáculos ao aumento da capacidade de transporte de cargas" por essa via.

A Marinha Brasileira (2013) afirma que há três considerações importantes sobre essas eclusas na situação atual, a saber:

- Todas as eclusas operando com grandes gargalos operacionais, e com apenas $35 \%$ a $57 \%$ da sua capacidade projetada. Como consequência as eclusas de Bariri e Nova Avanhandava são as que apresentam maior índice de congestionamento (tempo de espera);

- De todas as eclusas, Nova Avanhandava é a que opera com menor eficiência de capacidade, por não estar operando conforme o projeto do canal intermediário, que contempla cruzamento de comboios;

- O tempo médio de espera nas eclusas por viagem redonda é de 53,73 horas, sendo que o aceitável é de no máximo 15 horas (1,5 horas por eclusa).

Esse estudo faz a observação de que "se não houver melhorias no sistema de eclusas, até no ano de 2017, com entrada de comboios, o tempo de espera saltará para 133, 42 horas, inviabilizando o transporte na hidrovia" (Marinha, 2013). Assim, eles elaboraram um plano de trabalho proposto pelos armadores. Para a eclusa de Nova Avanhandava há a proposta para retomada de cruzamento de comboios vazios e carregados no Canal Intermediário.

Ribeiro et all. (2008) analisaram o trabalho de Lave e DeSalvo (1968) para avaliar a capacidade de transporte da Hidrovia Tietê-Paraná. A partir disso, desenvolveram dois modelos matemáticos: um baseado em teoria das filas e outro de simulação computacional. No decorrer da sua pesquisa, eles chegaram à constatação de que "a capacidade da hidrovia pode ser medida no número de chatas que podem passar pela eclusa durante o período adotado, normalmente de 1 ano". Com base nisso, este trabalho visa identificar o impacto do custo de transporte na eficiência do setor hidroviário, considerando o comboio ideal para navegação na eclusa de Nova Avanhandava, com o objetivo de aumentar a sua capacidade e produtividade, tornando mais viável o negócio de agência marítima. 


\subsection{Valor do custo de transporte e desafios}

A execução do transporte marítimo tem como remuneração o que se chama de frete, que é equivalente ao transporte de mercadoria entre dois portos distintos. "Os custos de frete são condicionados a algumas variáveis como o peso da carga, a quantidade, o volume, o tipo da carga, o valor venal, a distância entre dois portos, o tipo de embalagem a ser utilizado, etc" (PUC, SD). A tabela 1 traz informações sobre os tipos de cobrança:

Tabela 1: Tipos de taxas e Sobretaxas de Frete Marítimo

Tipo de taxas e sobretaxas

Heavy Lift Charge

(Taxa sobre Volume Pesado)

\section{Extra Lenght Charge}

(Taxa sobre Volume com Dimensões Excepcionais)

Forma de cobrança

Cobrado sobre volumes com excesso de peso e que irão exigir cuidados e equipamentos especiais.

Cobrado sobre volumes de difícil
movimentação em face de suas dimensões fora do padrão normal.

Cobrado sobre o valor da mercadoria, em virtude de seu alto valor unitário, pela responsabilidade adicional em que o armador incorrerá no caso de acidentes, avarias, etc. Cobrado pela espera para atracação do navio devido congestionamento do porto.

Cobrado quando na região há alguma guerra se desenvolvendo, ou perspectivas de que venha a ocorrer, pois o navio poderá ser envolvido e sofrer avarias ou inviabilizar sua operação.

Cobrado devido altos valores de combustível.

Bunker Surcharge

(Sobretaxa de combustível)

Fonte: Keedi e Mendonça (2003) apud PUC (SD)

Atualmente há a busca pela diminuição da tarifa portuária, principalmente devido à competitividade entre os portos, e que "os principais custos estão relacionados ao custo de agenciamento, o custo de entrada e saída das embarcações e os custos relativos à movimentação de carga no porto público ou terminal de contêiner" (PUC, SD). Em relação aos armadores, tem-se o custo de agenciamento, que é relativo ao seu serviço prestado, antes, durante e após a escala no navio no porto. "O custo é de responsabilidade do armador e geralmente pago considerando o volume de carga movimentada neste porto" (PUC, SD).

Em seu trabalho, Gonçalves (2008), considera a composição dos custos de transportes, em que inclui o modo hidroviário. Para o cálculo do custo de transporte ele adota o modelo proposto por Novaes (1976). Os parâmetros de entrada considerados foram do ano de 2006. O autor considerou a embarcação Tietê-Paraná e a Paraguai-Paraná. Neste trabalho será considerada apenas a primeira, mais especificadamente no rio Tietê. Comboio tipo Tietê, formado por grupo de chatas em linha mais 01 (um) empurrador, com comprimento total de $137 \mathrm{~m}$, boca de $11 \mathrm{~m}$ e calado de 2,70 m; e comboio tipo Tietê-Duplo, formado por grupo de chatas em linha, lado a lado, mais 01 (um) empurrador, com comprimento total de $137 \mathrm{~m}$, boca de $22 \mathrm{~m}$ e calado de $2,70 \mathrm{~m}$. "O trabalho adota um comboio constituído por 4 barcaças com capacidade de mil toneladas de carga cada uma, totalizando assim 4 mil toneladas. Desta forma, é necessária a realização de desmembramento na passagem das eclusas e em algumas pontes" (Gonçalves, 2008). Para o cálculo do frete, considerou- 
se o comboio-tipo Tietê-Paraná, empurrador de 900 hp e barcaças 4x1000 toneladas. O custo anual de rastreamento considerado foi de $\mathrm{R} \$ 14.400,00$. Os dados utilizados estão contidos na tabela 2 :

Tabela 2- Custos do comboio Tietê-Paraná

\begin{tabular}{|c|c|c|}
\hline \multicolumn{3}{|l|}{ Parâmetros de custos } \\
\hline Estáticos & Unidade & Valor \\
\hline Número de empurradores & Und & 1,00 \\
\hline Número de chatas & Und & 4,00 \\
\hline Custo de aquisição do empurrador & $\mathrm{R} \$$ & $2.790 .000,00$ \\
\hline Custo de aquisição das chatas & $\mathrm{R} \$$ & $600.000,00$ \\
\hline Taxa de retorno do capital & $\%$ & 0,12 \\
\hline Valor residual do custo de aquisição & $\%$ & 0,10 \\
\hline Vida útil do empurrador & Anos & 20,00 \\
\hline Vida útil das chatas & Anos & 20,00 \\
\hline Capacidade de carga do comboio & Ton & $4.000,00$ \\
\hline Potência instalada do motor & hp & 900,00 \\
\hline Custo do combustível & R\$/litro & 1,80 \\
\hline Custo do lubrificante & $\mathrm{R} \$ /$ litro & 5,00 \\
\hline Consumo de combustível por dia & litro/dia & $4.368,00$ \\
\hline Consumo do lubrificante por dia & litro/dia & 10,56 \\
\hline Taxa de seguro anual do empurrador & $\%$ & 0,02 \\
\hline Taxa de seguro anual das chatas & $\%$ & 0,02 \\
\hline Percentual do custo de manutenção do empurrador & $\%$ & 0,04 \\
\hline Percentual do custo de manutenção das chatas & $\%$ & 0,025 \\
\hline Número de tripulantes & Und & 8,00 \\
\hline Salário total da tripulação & $\mathrm{R} \$$ & $18.595,00$ \\
\hline Encargos sociais & $\%$ & 2,10 \\
\hline Custo da alimentação diária por tripulante & $\mathrm{R} \$$ & 10,00 \\
\hline Taxa de lucro & $\%$ & 15,00 \\
\hline Custo de Administração & $\%$ & 35,00 \\
\hline Dinâmicos & Unidade & Valor \\
\hline Dias de operação por ano & Dias & 360,00 \\
\hline Fator de utilização potência motor & $\%$ & 65,00 \\
\hline Número de viagens & Und & 1,00 \\
\hline Total da carga transportada no período & Ton & $594.000,00$ \\
\hline
\end{tabular}

Fonte: Gonçalves (2008)

A partir desses dados o autor determinou alguns custos gerais anuais da operação, conforme mostrados na tabela 3:

Tabela 3- Custos anuais de operação

\begin{tabular}{lr}
\hline Custo Anual & Valor (R\$) \\
\hline Custo de Capital Anual (CC) & $608.133,24$ \\
Custo do Seguro Anual (CS) & $103.800,00$ \\
Custo Anual de Tripulação (CTR) & $468.594,00$ \\
Custo de Alimentação Anual (CA) & $28.800,00$ \\
Custo de Manutenção e Reparo Anual (CMR) & $337.250,00$ \\
Custo de Administração Anual (CAD) & $292.160,40$ \\
Custo Anual de Combustível, Lubrificantes e Outros (CCL) & $2.971 .987,00$ \\
Custo Anual de Rastreamento (CAR) - valor fixo & $14.400,00$ \\
\hline
\end{tabular}


Fonte: Gonçalves (2008)

Considerando os dados acima foi possível chegar ao preço final do custo diário por tonelada e por quilômetro. Para isso calculou-se alguns custos, utilizando as seguintes equações (resultados na Tabela 4):

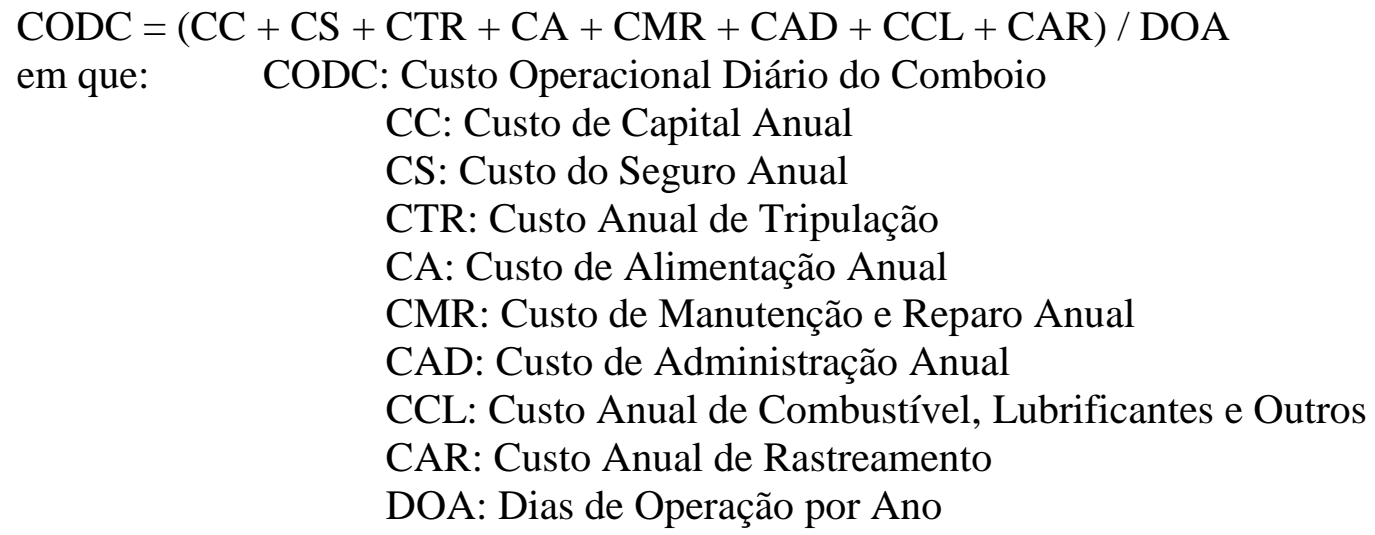

em que: $\quad$ Ckm: Custo por Quilômetro

$$
\mathrm{Ckm}=(\mathrm{CODC}) /(24 * 7,5)
$$

CODC: Custo Operacional Diário do Comboio

Tabela 3- Custos anuais de operação - 4 chatas

\begin{tabular}{lr}
\hline Custos diários & Valor (R\$) \\
\hline Custo Operacional Diário do Comboio & $13.403,00$ \\
Custo Diário do Comboio Parado & $5.147,88$ \\
Custo Diário por Tonelada & 3,35 \\
Custo por Quilômetro & 74,46 \\
\hline
\end{tabular}

Efetuando-se os cálculos para o comboio de duas e seis chatas tem-se os valores da tabela 4:

Tabela 4- Custos anuais de operação para 2 e 6 chatas

\begin{tabular}{lrr}
\hline Custos & 2 chatas $(\mathrm{R} \$)$ & 6 chatas $(\mathrm{R} \$)$ \\
\hline
\end{tabular}




\begin{tabular}{lcc}
\hline Custo do Seguro Anual (CS) & $67.800,00$ & $163.800,00$ \\
Custo de Manutenção e Reparo Anual (CMR) & $220.350,00$ & $532.350,00$ \\
Custo Operacional Diário do Comboio & $12.978,40$ & $14.111,74$ \\
Custo Diário do Comboio Parado & $4.722,88$ & $5.856,22$ \\
Custo Diário por Tonelada & 6,49 & 2,35 \\
Custo por Quilômetro & 72,10 & 78,40 \\
\hline
\end{tabular}

Baseado no trabalho de Gonçalves (2008) pode-se fazer os cálculos do tempo de viagem e do valor do custo de transporte (conforme mostrado nas tabelas 5). Considerou-se três tipos de comboios, com 2 chatas, com 4 chatas (modelo usual) e com 6 chatas, com o objetivo de verificar qual apresenta melhor rentabilidade para o armador, elaborou-se as tabelas 5, 6 e 7.

Tabela 5: Cálculo do tempo de viagem

\begin{tabular}{cccccc}
\hline $\begin{array}{c}\text { Tempo gasto } \\
\text { com } \\
\begin{array}{c}\text { eclusagem } \\
(\text { dia })\end{array}\end{array}$ & $\begin{array}{c}\text { Velocidade } \\
(\mathrm{km} / \mathrm{h})\end{array}$ & $\begin{array}{c}\text { Distância }(\mathrm{km}) \\
\text { São Simão/GO } \\
\mathrm{a}\end{array}$ & $\begin{array}{c}\text { Tempo de } \\
\text { deslocamento } \\
(\text { dia })\end{array}$ & $\begin{array}{c}\text { Tempo Total } \\
\text { Pederneiras/SP }\end{array}$ & $\begin{array}{c}\text { Total de } \\
\text { viagens no } \\
\text { ano }\end{array}$ \\
\hline $\begin{array}{c}(53,73 / 24) \\
2,239\end{array}$ & $\begin{array}{c}(1,852 * 7)= \\
12,964\end{array}$ & 640 & $\begin{array}{c}(640 / 12,964) / 24 \\
=2,057\end{array}$ & $\begin{array}{c}(2,057+2,239) \\
=4,296\end{array}$ & $\begin{array}{c}(360 / 4,296) \\
=83\end{array}$ \\
\hline
\end{tabular}

Tabela 6: Cálculo do valor do custo de transporte

\begin{tabular}{|c|c|c|c|c|c|}
\hline $\begin{array}{l}\text { Valor do } \\
\text { custo de } \\
\text { transporte } 1 \\
\text { (diário } \\
\text { tonelada) }\end{array}$ & $\begin{array}{c}\text { Valor do } \\
\text { custo de } \\
\text { transporte } 2 \\
\quad(\mathrm{~km} \\
\text { navegado) }\end{array}$ & Comboio & $\begin{array}{c}\text { Capacidade } \\
\text { do Comboio } \\
\text { (toneladas) }\end{array}$ & $\begin{array}{c}\text { Valor de uma } \\
\text { viagem (CT 1) }\end{array}$ & $\begin{array}{c}\text { Valor de } \\
\text { uma viagem } \\
\text { (CT 2) }\end{array}$ \\
\hline 6,49 & 72,10 & $\begin{array}{l}2 \text { chatas }-1 \\
\text { empurrador }\end{array}$ & 2.000 & $\begin{array}{c}(2000 * 6,49 * 4,339) \\
=56.320,22\end{array}$ & $\begin{array}{l}(72,10 * 640) \\
=46.144,00\end{array}$ \\
\hline 3,35 & 74,46 & $\begin{array}{l}4 \text { chatas }-1 \\
\text { empurrador }\end{array}$ & 4.000 & $\begin{array}{c}(4000 * 3,35 * 4,339) \\
=58.142,60\end{array}$ & $\begin{array}{l}(74,46 * 640) \\
=47.654,40\end{array}$ \\
\hline 2,35 & 78,40 & $\begin{array}{l}6 \text { chatas }-1 \\
\text { empurrador }\end{array}$ & 6.000 & $\begin{array}{c}(6000 * 2,35 * 4,339) \\
=61.179,90\end{array}$ & $\begin{array}{l}(78,40 * 640) \\
=50.176,00\end{array}$ \\
\hline
\end{tabular}

Tabela 7: Cálculo da receita baseado no valor do custo de transporte

\begin{tabular}{cccc}
\hline $\begin{array}{c}\text { Total da receita no } \\
\text { ano/Tipo de comboio }\end{array}$ & Comboio -2 chatas & Comboio -4 chatas & Comboio -6 chatas \\
\hline CT 1 $(\mathrm{R} \$)$ & $(56.320,22 * 83)=$ & $(58.142,60 * 83)=$ & $(61.179,90 * 83)=$ \\
& $4.674 .578,26$ & $4.825 .835,80$ & $5.077 .931,70$ \\
\hline CT 2 $(\mathrm{R} \$)$ & $(46.144,00 * 83)=$ & $(47.654,40 * 83)=$ & $(50.176,00 * 83)=$ \\
& $3.829 .952,00$ & $3.955 .315,20$ & $4.164 .608,00$ \\
\hline
\end{tabular}

\section{RESULTADOS E DISCUSSÃO}

A partir dos cálculos realizados no tópico anerior, que tem o enfoque no preço final da embarcação, chega-se ao resultado de que o comboio composto por 4 chatas e 1 empurrador (Tipo Tietê-Duplo) é mais viável tanto no custo de transporte de custo diário de tonelada quanto para o custo de transporte por quilômetro navegado. Os valores apresentam pouca diferença e a capacidade de carga transportada é o dobro em relação ao comboio de 2 chatas (Tipo Tietê). Porém, outros 
fatores são importantes a considerar na busca de identificar qual o melhor tipo de comboio para operar na hidrovia Tietê-Paraná, mas especificadamente na eclusa Nova Avanhandava.

Considerando um total de 83 viagens anuais, tem-se uma carga transportada de 166.000 ton para o comboio de 2 chatas, 332.000 ton para o comboio de 4 chatas e de 498.000 ton para o comboio de 6 chatas. Assim, para o CT 1 tem-se um custo por tonelada transportada de 28,16 reais, 14,54 reais e 10,20 reais para os comboios de 2, 4 e 6 chatas, respectivamente. Para o CT 2 temos 23,07 reais, 11,91 reais e 8,36 reais, respectivamente. Assim, em relação ao aspecto custo de transporte, o comboio mais viável para navegação é o formado por 6 chatas.

Padovezi (2003) adaptou a formulação de Howe (Christopoulos \& Latorre, 1983) para comboios fluviais para utilização de valores em unidades métricas, para assim determinar a potência efetiva do casco, obtendo a seguinte equação:

$P_{E}=0,14426 \cdot F \cdot e^{\frac{0,445}{h-T_{C}}} \cdot\left(\frac{T_{C}}{0,3048}\right)^{0,6+\frac{15,4}{W-B_{C}}} \cdot L_{C}^{0,38} \cdot B_{C}^{1,19} \cdot V^{3}$

Em que: $\quad F$ : fator de formação do comboio

h: profundidade média da hidrovia

$\mathrm{T}_{\mathrm{C}}$ : calado médio do comboio

W: largura média da hidrovia

$\mathrm{B}_{\mathrm{C}}$ : boca total do comboio

$\mathrm{V}$ : velocidade média do comboio

Considerando o valor fixo de consumo de óleo diesel de $156 \mathrm{~g} / \mathrm{kWe} . \mathrm{hr}$ e de óleo lubrificante de $1,2 \mathrm{~g} / \mathrm{kW} . \mathrm{hr}$, margens de $28 \%$, custo de óleo diesel de $\mathrm{R} \$ 1.600,00$ por tonelada e de óleo lubrificante de $\mathrm{R} \$ 20.000,00$ por tonelada utilizados no trabalho de Rodrigues e Lemgruber (S/D), obtiveram-se os resultados mostrados na tabela 8:

Tabela 8- Comparação entre comboios com 2, 4 e 6 chatas

\begin{tabular}{lrrr}
\hline Tipo do comboio & $1 \times 2$ & $2 \times 2$ & $3 \times 2$ \\
\hline Linhas & 1 & 2 & 3 \\
Colunas & 2 & 2 & 2 \\
Número de balsas & 2 & 4 & 6 \\
F & 0,05 & 0,045 & 0,07 \\
H $(\mathrm{m})$ & 3,1 & 3,1 & 3,1 \\
Tc $(\mathrm{m})$ & 2,7 & 2,7 & 2,7 \\
$\mathrm{~W}(\mathrm{~m})$ & 300 & 300 & 300 \\
$\mathrm{Bc}(\mathrm{m})$ & 22 & 22 & 22 \\
Lc $(\mathrm{m})$ & 80 & 140 & 200 \\
V (m/s) & 2,8 & 2,8 & 2,8 \\
Potência efetiva (kW) & 407 & 453 & 807 \\
Potência dos grupos geradores (kW) & 521 & 580 & 1033 \\
Consumo de óleo diesel (t/dia) & 1,95 & 2,17 & 3,87 \\
Consumo de óleo lubrificante (t/dia) & 0,02 & 0,02 & 0,03 \\
Custo/óleo (R\$/ano) & $1.231 .821,90$ & $1.371 .339,19$ & $2.442 .829,51$ \\
\hline
\end{tabular}

De acordo com o MMA (2011) e Zary (2015), a emissão de CO2 por kg/l é de 2,671 para veículos de ciclo diesel. Considerando o consumo de óleo encontrado (mostrado na tabela 8) e 360 dias no ano, tem-se uma emissão anual de $2.232 .192,86 \mathrm{~kg} / \mathrm{l}$ para o comboio de 2 chatas, 2.484.030,00 kg/l para o de 4 chatas e 4.430.044,29 kg/l para o de 6 chatas. Encontrou-se nesse trabalho um total de 83 viagens/ano e adotou-se uma capacidade do comboio de 1000 ton por chata. Assim, a emissão de cada comboio por tonelada transportada é de 0,0134 kg de CO2/kg de carga, 
0,0075 kg de CO2/kg de carga e 0,0089 kg de CO2/kg de carga, respectivamente. Nesse aspecto, o comboio composto por 4 chatas é superior, mas apresenta pouca diferença em relação ao de 6 chatas.

\section{CONSIDERAÇÕES FINAIS}

Este trabalho teve como objetivo avaliar o impacto no custo de transporte e na emissão de CO2 na atmosfera do setor hidroviário a partir do tipo de comboio escolhido para navegação, em que se fez um estudo de caso na hidrovia Tietê-Paraná e na eclusa Nova Avanhandava para verificar se há ou não essa influência. Analisou-se os comboios compostos por 2, 4 e 6 chatas mais 1 empurrador. Como hipótese considerou-se que haveria diferença no valores. Findado o estudo, o objetivo foi alcançado e comprovou-se que a hipótese é verdadeira, tendo assim o problema de pesquisa respondido.

O principal método para verificar a veracidade da hipótese e alcançar o objetivo proposto foi identificar a escolha do tipo de comboio que traz mais rentabilidade, sob os aspectos valor do custo de transporte e emissão de $\mathrm{CO} 2$ na atmosfera. Teve-se como base o trabalho desenvolvido por Gonçalves (2008). Com a conclusão deste trabalho, chegou-se ao resultado de que o comboio composto por 6 chatas e 1 empurrador (Tipo Tietê-Duplo) é mais viável tanto em relação ao custo diário de tonelada quanto para o custo de transporte por quilômetro navegado, e apresentar uma emissão de $\mathrm{CO} 2$ muito próxima do comboio de 4 chatas.

No entanto, é possível analisar outros aspectos, a exemplo da capacidade da hidrovia, as potencialidades do setor hidroviário brasileiro, as eclusas da hidrovia, o nicho de mercado, dentre outros aspectos.

\section{REFERÊNCIAS}

Administração dos portos de Paranaguá e Antonina - APPA. Disponível em: <http://www.portosdoparana.pr.gov.br/modules/conteudo/conteudo.php?conteudo=172>. Acessado em 10 de julho de 2015 .

Agência Nacional de Águas - ANA. Ministério do Meio Ambiente. A navegação interior e sua interface com o setor de recursos hídricos. Superintendência de Usos Múltiplos. Brasília-DF, maio, 2005. Disponível em: <http://arquivos.ana.gov.br/planejamento/planos/pnrh/VF\%20Navegacao.pdf>. Acessado em 25 de agosto de 2014.

Agência Nacional de Transportes Aquaviários - ANTAQ. Transporte Aquaviário no Brasil. Disponível em: <http://www.antaq.gov.br/portal/pdf/palestras/10-ApresentacaoLuisCavalcanti.pdf>. Acessado em 24 de agosto de 2014.

de 2014.

Disponível em: <http://www.antaq.gov.br/portal/perguntasfrequentessnm.asp>. Acessado em: 25 de agosto

Hidrovia Paraná-Tietê - Consequências da interrupção da navegação. Disponível em: <http://www.antaq.gov.br/portal/pdf/Palestras/20140617HidroviaParanaTiete.pdf>. Acessado em 25 de agosto de 2014.

Brasil. Lei $n^{\circ}$ 9.432, de 8 de janeiro de 1997. Dispõe sobre a ordenação do transporte aquaviário e dá outras providências. Diário Oficial da União. Disponível em: < http://www.planalto.gov.br/ccivil_03/LEIS/L9432.htm>. Acessado em: 10 jul. 2015.

Brasil. Lei $n^{\circ}$ 9.537, de 11 de dezembro de 1997. Dispõe sobre a osegurança do tráfego aquaviário em águas sob jurisdição e dá outras providências. Diário Oficial da União. Disponível em: < http://www.planalto.gov.br/ccivil_03/LEIS/L9432.htm>. Acessado em: 10 jul. 2015.

GONÇALVES, G. I..Perspectivas de integração modal rodo-hidro-ferroviária na exportação de produtos agrícolas e minerais no estado de Mato Grosso do Sul. 2008. 152 p. Dissertação (mestrado). Escola de Engenharia de São Carlos da Universidade de São Paulo, São Carlos, 2008. 
Marinha do Brasil. Ministério de defesa. Disponível em: 〈http://www.marinha.mil.br/>. Acessado em: 27 de agosto de 2014.

Ministério dos Transportes. Resumo Informativo da Eclusa de Nova Avanhandava. Disponível em: <http://www2.transportes.gov.br/bit/04-hidro/4-barra-eclu/eclu/reg-sud/GECLAVAN.HTM>. Acessado em: 24 de agosto de 2014.

Ministério dos Transportes. Plano Nacional de Logísticas e Transportes - PNLT. Relatório Final. Secretaria de Política Nacional de Transportes. Brasília, 2012.

MMA - Ministério do Meio Ambiente. Inventário Nacional de Emissões Atmosféricas por veículos automotores rodoviários. Relatório Final. Secretaria de Mudanças Climáticas e Qualidade Ambiental.Departamento de Mudanças Climáticas. Gerência de Qualidade do Ar, 2011.

NELSON JÚNIOR, F. F. A Hidrovia Tietê-Paraná e a intermodalidade no Estado de São Paulo. Universidade Esadual Paulista. Faculdade de Ciências e Tecnologia. Presidente Prudente, 2008.

PADOVEZI, Carlos Daher. Conceito de embarcações adaptadas a via aplicado a navegação fluvial no Brasil. Tese (Doutorado em Engenharia) Escola Politécnica da Universidade de São Paulo, Engenharia Naval e Oceânica. 2003.

PLÁCIDO, Daison Rafael (2007). Análise dos prejuízos causados aos armadores pelos gargalos logísticos existentes no porto de Rio Grande. Disponível em: <http://biblioteca.unilasalle.edu.br/docs_online/tcc/graduacao/administracao/2007/drplacido.pdf>. Acessado em 24 de agosto de 2014.

Porto de Santos. Disponível em: <http://www.portodesantos.com.br/imprensa.php?pagina=resano>. Acessado em 10 de julho de 2015.

PUC-Rio (S/D) O porto e o terminal de contêiner. Disponível em: <http://www.maxwell.vrac.pucrio.br/9451/9451_5.PDF>. Acessado em 25 de agosto de 2014.

RIBEIRO, E. S. et al.. Avaliação da capacidade da Hidrovia Tietê-Paraná e proposição de mecanismo para redução dos tempos de eclusagem. $22^{\circ}$ Congresso Nacional de transporte aquaviário, construção naval e offshore - SOBENA 2008.

RODRIGUES, R. A. LEMGRUBER, T. (S/D) Projeto de sistemas oceânicos 2. Relatório 1.Engenharia Naval e Oceânica. COPPE/Politécnica/UFRJ. $\quad$ Disponível em: < http://www.oceanica.ufrj.br/deno/prod_academic/relatorios/2008/Ricardo_Thiago/relat1/>. Acessado em 11 de julho de 2015.

SANTANA, W. A. TACHIBANA, T.. Caracterização dos elementos de um projeto hidroviário, vantagens, aspectos e impactos ambientais para a proposição de metodologias técnico-ambientais para o desenvolvimento do transporte comercial de cargas nas hidrovias brasileiras. 2004. Disponível em: < http://www.uff.br/engevista/3_6Engevista6.pdf>. Acessado em 30 de agosto de 2014.

ZARY, B. C. S. Procedimento de auxílio ao estudo de viabilidade técnica, econômica e ambiental de projetos de transporte urbano coletivo Dissertação de Mestrado. Rio de Janeiro: Instituto Militar de Engenharia, 2015. 